\title{
Lipossarcoma esplênico em um cão
}

\author{
Splenic liposarcoma in a dog
}

\author{
Marluce de Macedo Cavassani Montagna ${ }^{1}$ Sandra Bernal Nicolau ${ }^{2}$ \\ Ana Paula Massae Nakage ${ }^{3}$ Adriana Coelho de Souza ${ }^{4}$ Jair Rodini Engracia Filho $^{5}$
}

\section{- NOTA -}

\section{RESUMO}

O presente trabalho visa relatar um caso de lipossarcoma canino, por se tratar de uma rara neoplasia em cães. Um cão, fêmea, Fila Brasileiro, 9 anos de idade com $47 \mathrm{~kg}$ apresentou anorexia, vômito e apatia. A palpação abdominal revelou massa na região mesogástrica, e o paciente morreu antes da celiotomia exploratória. À necrópsia, constatou-se massa medindo $10 \times 10 \times 13 \mathrm{~cm}$ aderida ao baço. O diagnóstico histológico foi lipossarcoma.

Palavras-chave: neoplasia, abdômen, baço.

\section{ABSTRACT}

A case of liposarcoma is reported in a 9year-old female Brazilian Fila with $46 \mathrm{~kg}$, which was presented with anorexia, vomiting and apathy. Physical examination revealed the presence of an abdominal mass in the mesogastric region. The patient died before exploratory celiotomy. At necropsy a mass with $10 \times 10$ $x 13 \mathrm{~cm}$ attached to the capsule of the spleen was observed. Histopathological examination confirmed liposarcoma.

Key words: neoplasm, abdomen, spleen.
O lipossarcoma é uma neoplasia maligna de lipoblastos e, ao contrário do lipoma, é de ocorrência rara nos animais domésticos (STRAFUSS \& BOZARTH, 1973; DOSTER, et al., 1986; LEWIS et al., 1991). Acredita-se que o lipossarcoma não resulte da transformação maligna de lipomas pré-existentes, porém a etiologia desses tumores não foi ainda identificada (DOSTER et al., 1986; McCARTHY et al., 1996). O tumor acomete principalmente cães com idade média de 8 anos, sendo mais comum em cadelas obesas (PULLEY \& STANNARD, 1990). Parece não haver predisposição racial, embora ACKERMAN \& SILVER (1984) citem que cães das raças Dachshund e Brittany Spaniel sejam predispostos.

Em cães, o lipossarcoma apresenta predileção por tecidos subcutâneos e tecidos moles profundos, entretanto, esta neoplasia também tem sido identificada na cavidade abdominal e na torácica (MESSICK \& RADIN, 1989; LEWIS et al., 1991). Hemangiossarcomas, hemangioendoteliomas e hemangiomas são as neoplasias primárias mais comumente relatadas no baço de cães, as quais

\footnotetext{
${ }^{1}$ Médico Veterinário, Mestrando, Programa de Pós-graduação em Cirurgia Veterinária, Faculdade de Ciências Agrárias e Veterinárias de Jaboticabal (FCAVJ), Universidade Estadual Paulista (UNESP). Rua Guiana Inglesa, 450, apto 81, Ed. Manchester, 14075-210, Ribeirão Preto, SP. E-mail: mcavassani@hotmail.com. Autor para correspondência. ${ }^{2}$ Médico Veterinário, Campus Veterinário, Centro Universitário Barão de Mauá, Ribeirão Preto, SP.

${ }^{3}$ Médico Veterinário, doutorando, Programa de Pós-graduação em Medicina Veterinária, FCAVJ, UNESP, Jaboticabal.

${ }^{4}$ Médico Veterinário, Doutor, Professor de Patologia Veterinária, Centro Universitário Barão de Mauá, Ribeirão Preto, SP

${ }^{5}$ Médico Veterinário, Mestre, Professor de Patologia Veterinária, Centro Universitário Barão de Mauá, Ribeirão Preto, SP.
} 
apresentam células tumorais semelhantes às endoteliais (SEARCY, 1998; MOULTON \& HARVEY, 1990; JONES et al., 2000).

Assim como outros tumores mesenquimais, os lipossarcomas tendem a ser localmente invasivos, porém possuem capacidade metastática baixa. Sítios de metástases incluem os pulmões, fígado e membros posteriores. O tratamento consiste em exérese com margem cirúrgica de $3 \mathrm{~cm}$ de tecido sadio e o prognóstico depende da extensão da neoplasia no local afetado (McCARTHY et al., 1996).

O presente trabalho visa relatar um caso de lipossarcoma canino, por se tratar de uma rara neoplasia em cães. Foi atendido no Centro Universitário “Barão de Mauá”, Campus da Medicina Veterinária em Ribeirão Preto/SP, um cão Fila Brasileiro, fêmea, 9 anos de idade, com $47 \mathrm{~kg}$. O histórico incluia anorexia há 5 dias, vômitos, apatia e dificuldade de locomoção. Ao exame físico, o paciente apresentou hipertermia $\left(40,5^{\circ} \mathrm{C}\right)$, distensão abdominal, caquexia, desidratação (8\%) e mucosas hipocoradas. À palpação abdominal, notou-se presença de excesso de líquido na cavidade abdominal e massa firme, não flutuante e arredondada, localizada na região mesogástrica.

As avaliações hematológicas consistiram nas contagens globais de hemácias, leucócitos e plaquetas pela técnica de hemocitômetro, na determinação do hematócrito e na contagem diferencial de leucócitos em esfregaços sangüíneos corados com May Grünwald-Giemsa (MGG). As avaliações bioquímicoséricas foram proteínas totais e fibrinogênio por refratometria, uréia UV cinética e creatinina colorimétrica com o auxílio de kits (Biotécnica ${ }^{a}$ ) e leitura espectrofotométrica (Bioplus 200 ${ }^{\mathrm{b}}$ ).

O hemograma indicou anemia ( $\mathrm{He}=4,45$ $\mathrm{x} 10^{6} / \mathrm{mL}$ e $\mathrm{Ht}=28 \%$ ) relacionada ao hemoperitôneo observado à necrópsia; neutrofilia com desvio à

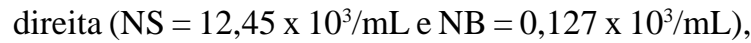
eosinopenia $\left(0 \times 10^{3} / \mathrm{mL}\right)$, linfopenia $\left(0,127 \times 10^{3} / \mathrm{mL}\right)$, caracterizando um leucograma de estresse (MEINKOTH \& CLINKENBEARD, 2000) e trombocitopenia $(130.000 / \mathrm{mL})$. As determinações bioquímicas revelaram azotemia (uréia: $118 \mathrm{mg} / \mathrm{dL}$ e creatinina: $1,9 \mathrm{mg} / \mathrm{dL}$ ), reportada por WEINSTEIN et al. (1989) e relacionada à hemorragia peritoneal provocada pelo lipossarcoma; hiperfibrinogemia (fibrinogênio absoluto: 4,27g/dL) e hiperproteinemia (9,4g/dL), asseveradas por LEWIS et al. (1991) e McCARTHY et al. (1996).

Ao exame radiográfico da cavidade abdominal, verificou-se imagem compatível com efusão abdominal. Não houve evidência de metástase no tórax. Estes achados são semelhantes aos descritos por
PULLEY \& STANNARD (1990), os quais relataram que geralmente os lipossarcomas infiltram localmente, sendo raro metástases.

O cão morreu antes que fosse realizada a celiotomia exploratória, sendo encaminhado para o setor de patologia do Campus Veterinário "Barão de Mauá”. Na necrópsia, observou-se hemoperitônio, contendo aproximadamente 3L de líquido serosangüinolento, e uma grande massa brancoamarelada nodular, com consistência firme, inserida na superfície do baço, e apresentando aderências ao mesentério. Na área de inserção da neoplasia no baço, observou-se ulceração e hemorragia (Figura 1). Estas lesões, provavelmente, foram responsáveis pelo hemoperitônio, e conseqüente anemia observada no animal. Ao corte do tumor, notaram-se áreas hemorrágicas e outras amolecidas, semelhantemente aos relatos de LEWIS et al. (1991), os quais descreveram áreas de necrose e hemorragia no lipossarcoma. Não foram observados focos tumorais em outros órgãos ou tecidos do animal.

Amostras do tumor foram colhidas para análise histológica. Os fragmentos foram fixados por 24 horas em formol a 10\% tamponado com fosfato $\mathrm{pH}$ 7,0. Em seguida, foram desidratados, diafanizados e incluídos em parafina, para o preparo de secções de $5 \mathrm{~mm}$ de espessura, coradas pela hematoxilina-eosina (HE). Os cortes foram examinados à microscopia de luz. Histologicamente, observaram-se células neoplásicas com grandes vacúolos lipídicos eosinofílicos, permeadas por células inflamatórias. Células tumorais com vacúolos citoplasmáticos finamente acidofílicos estavam infiltrando-se no parênquima esplênico, apresentando formato e tamanho variados (Figura 2). O diagnóstico de lipossarcoma foi confirmado pelo exame histopatológico. Têm sido relatados na literatura, alguns casos de lipossarcoma no baço de cães, com características semelhantes às descritas acima (SPANGLER et al., 1994; WEINSTEIN et al., 1989). Embora o aspecto macroscópico assemelhe-se aos nódulos esplênicos histiocíticos, descritos por SPANGLER \& KASS, (1998), os achados histopatológicos aqui verificados confirmam que a neoplasia primária se trata de um lipossarcoma.

O tratamento para neoplasias esplênicas consiste em esplenectomia. Entretanto, de acordo com WEINSTEIN, et al. (1989), em seu estudo com cães tratados cirurgicamente, a sobrevida após a cirurgia é muito pequena e grande parte dos animais morreu em menos de um ano, independentemente do tipo de tumor. 


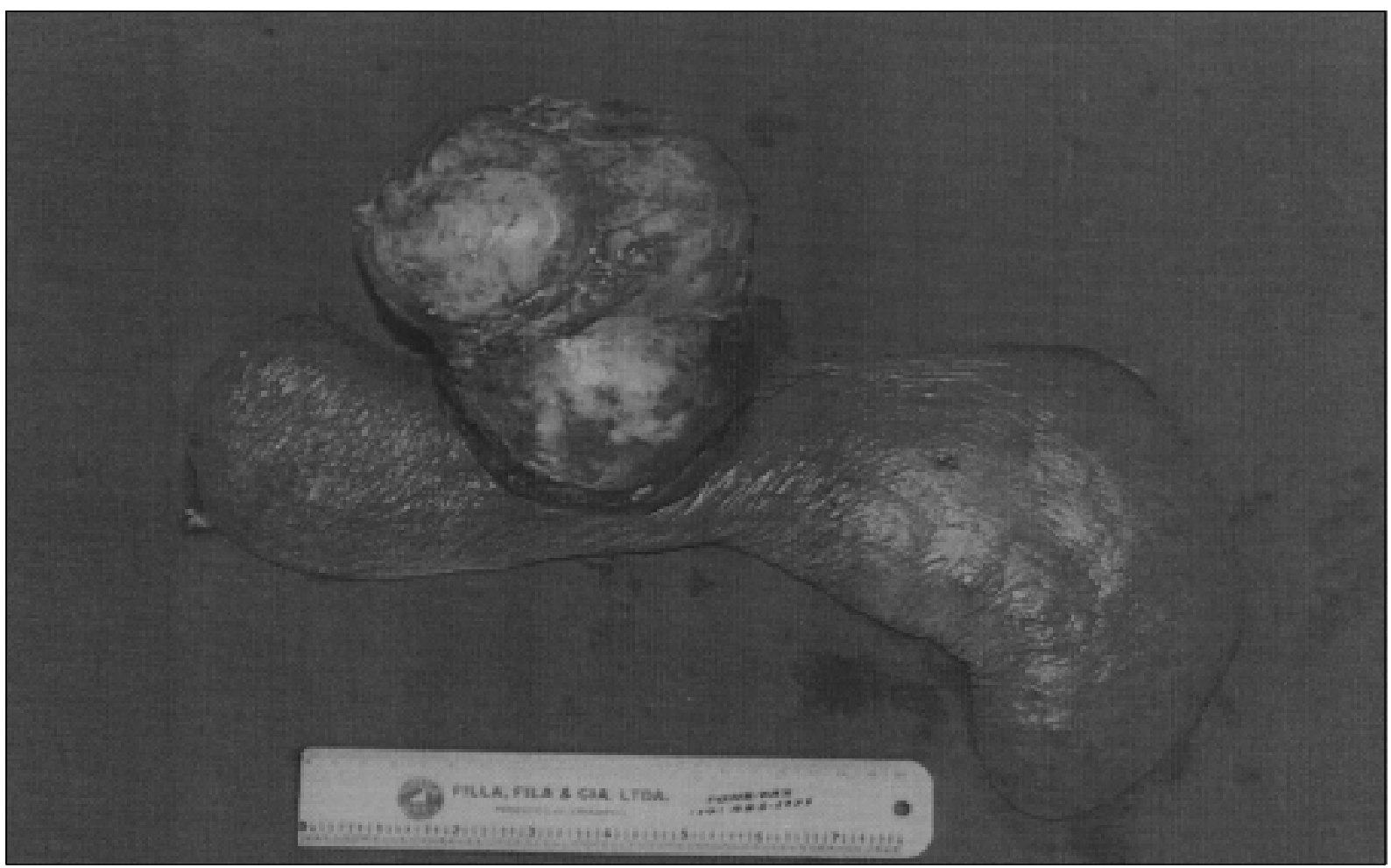

Figura 1 - Baço com esplenomegalia e massa multilobulada com aproximadamente 10 x 10 x 13cm aderida ao órgão.

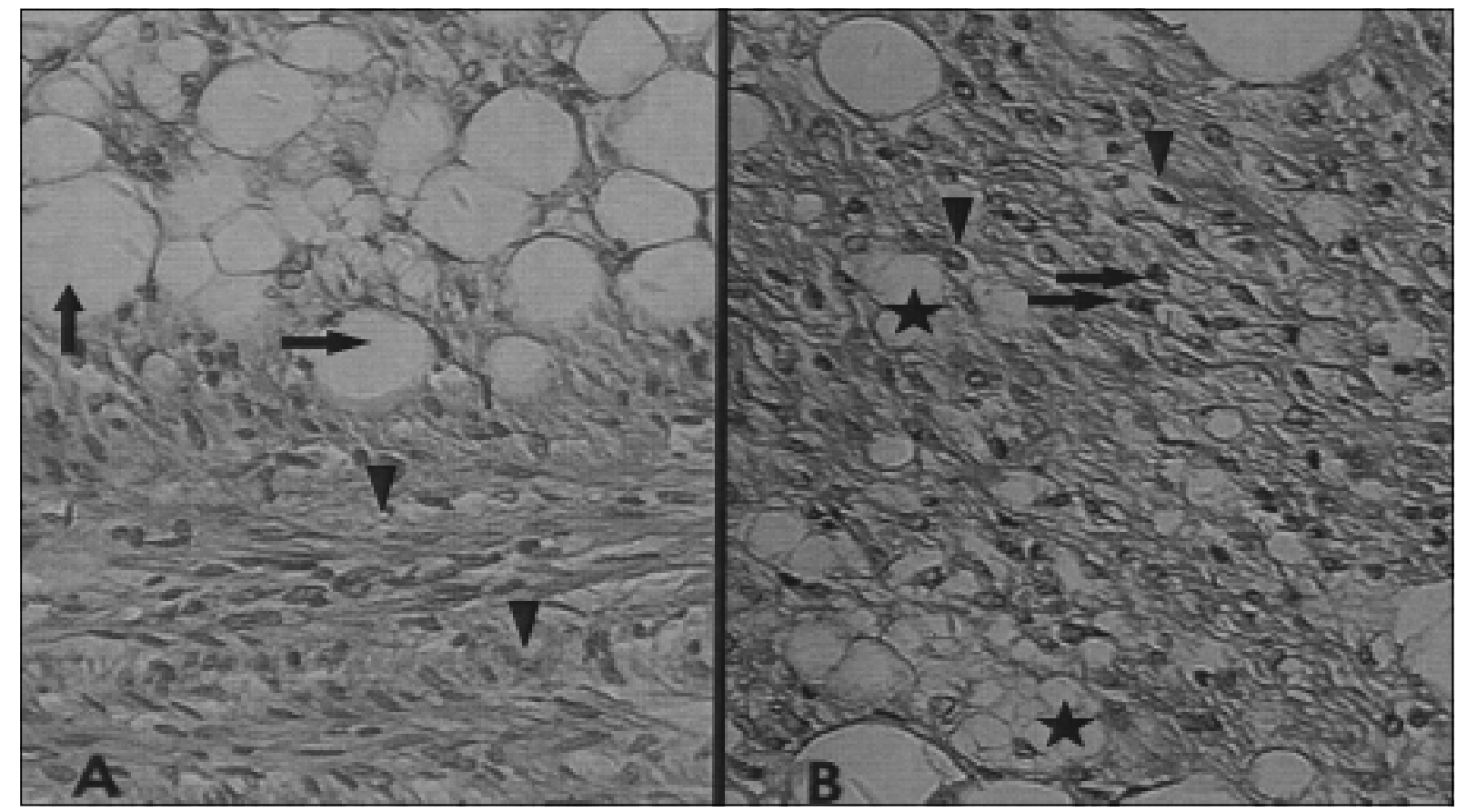

Figura 2 - A. Fotomicrografia de células neoplásicas arredondadas, apresentando grandes vacúolos no citoplasma (seta). Nota-se proliferação de tecido conjuntivo na neoplasia (cabeça de seta). B. Fotomicrografia de adipócitos neoplásicos com moderado pleomorfismo (cabeça de seta), apresentando pequenos vacúolos citoplasmáticos (estrela). Observar figuras de mitose (seta). (HE - $20 \mathrm{x}$ ). 
São necessários estudos mais aprofundados sobre os fatores etiológicos e clínicos dessa neoplasia, pois os lipossarcomas possuem curso clínico desfavorável. Entretanto, a realização de investigações sobre o assunto é parcialmente limitada dada à baixa casuística dessa enfermidade em animais. O prognóstico depende da extensão da neoplasia no local afetado (McCARTHY et al., 1996).

\section{FONTES DE AQUISIÇÃO}

${ }^{a}$ Biotécnica Ind. e Co. Ltda. - Varginha (MG), b Bioplus 200 - HB Labor - Ribeirão Preto (SP).

\section{REFERÊNCIASBIBLIOGRÁFICAS}

ACKERMAN, L.J.; SILVER, J.N. Abdominal liposarcoma in a dog. Modern Veterinary Practice, Santa Barbara, v.65, p.470, 1984.

DOSTER, A.R. et al. Canine liposarcoma. Veterinary Pathology, Washington, v.23, p.84-87, 1986.

JONES, et al. Sistema hêmico e linfático. In: Patologia veterinária. São Paulo : Manole, 2000. Cap.22, p.1027-1061.

LEWIS, D.D. et al. Extradural spinal liposarcoma in a dog. Journal American Veterinary Medical Association, Schaumburg,, v.199, n.11, p.1606-1607, 1991.

McCARTHY, P.E et al. Liposarcoma associated with a glass foreign body in a dog. Journal American Veterinary Medical Association, Schaumburg, v.209, n.3, p.612-614, 1996.

MEINKOTH, J.H.; CLINKENBEARD, K.D. Normal hematology of the dog. In: FELDMAN, B.F.; ZINKL, J.G; JAIN, N.C. Schalm's veterinary hematology. Philadelphia : Lippincott Williams \& Wilkins, 2000. p.1057-1063.
MESSICK, J.B.; RADIN, M.J. Cytologic and ultrastructural characteristics of a canine myxoid lipossarcoma. Veterinary Pathology, Washington, v.26, p.520-522, 1989.

MOULTON, J.E.; HARVEY, J.W. Tumors of the lymphoid and hemopoietic tissues. In: MOULTON, J.E. Tumors in domestic animals. 3.ed. Berkeley: University of California, 1990. Cap.6, p.23-82.

PULLEY, L.T.; STANNARD, A.A. Tumors of the skin and soft tissues. In: MOULTON, J.E. Tumors in domestic animals. 3.ed. Berkeley : University of California, 1990. Cap.2, p.23-82.

SEARCY, G.P. Sistema endócrino. In: CARLTON, W.W.; McGAVIN, M.D. Patologia veterinária especial de Thomson. Porto Alegre : Artmed, 1998. Cap.6, p.266-304.

SPANGLER, W.L. et al. Primary mesenchymal (Nonangiomatous/Nonlymphomatous) neoplasms occurring in the canine spleen: anatomic classification, immunohistochemistry, and mitotic activity correlated with patient survival. Veterinary Pathology, Washington, v.31, n.1, p.37-47, 1994.

SPANGLER, W.L.; KASS, P.H. Pathologic and prognostic characteristics of splenomegaly in dogs due to fibrohistiocytic nodules: 98 cases. Veterinary Pathology, Washington, v.35, n.6, p.488-498, 1998.

STRAFUSS, A.C.; BOZARTH, A.J. Liposarcoma in dogs. Journal American Animal Hospital Association, Lakewood, v.9, p.183-187, 1973.

WEINSTEIN M.J. et al. Nonangiogenic and nonlymphomatous sarcomas of the canine spleen: 57 cases (1975-1987). Journal American Veterinary Medical Association, Schaumburg, v.195, n.3, p.784788, 1989. 